\title{
Base Pair
}

National Human Genome Research Institute (NHGRI)

\section{Source}

National Human Genome Research Institute (NHGRI). Base Pair.

\begin{abstract}
A base pair is two chemical bases bonded to one another forming a "rung of the DNA ladder." The DNA molecule consists of two strands that wind around each other like a twisted ladder. Each strand has a backbone made of alternating sugar (deoxyribose) and phosphate groups. Attached to each sugar is one of four bases--adenine (A), cytosine (C), guanine (G), or thymine (T). The two strands are held together by hydrogen bonds between the bases, with adenine forming a base pair with thymine, and cytosine forming a base pair with guanine.
\end{abstract}



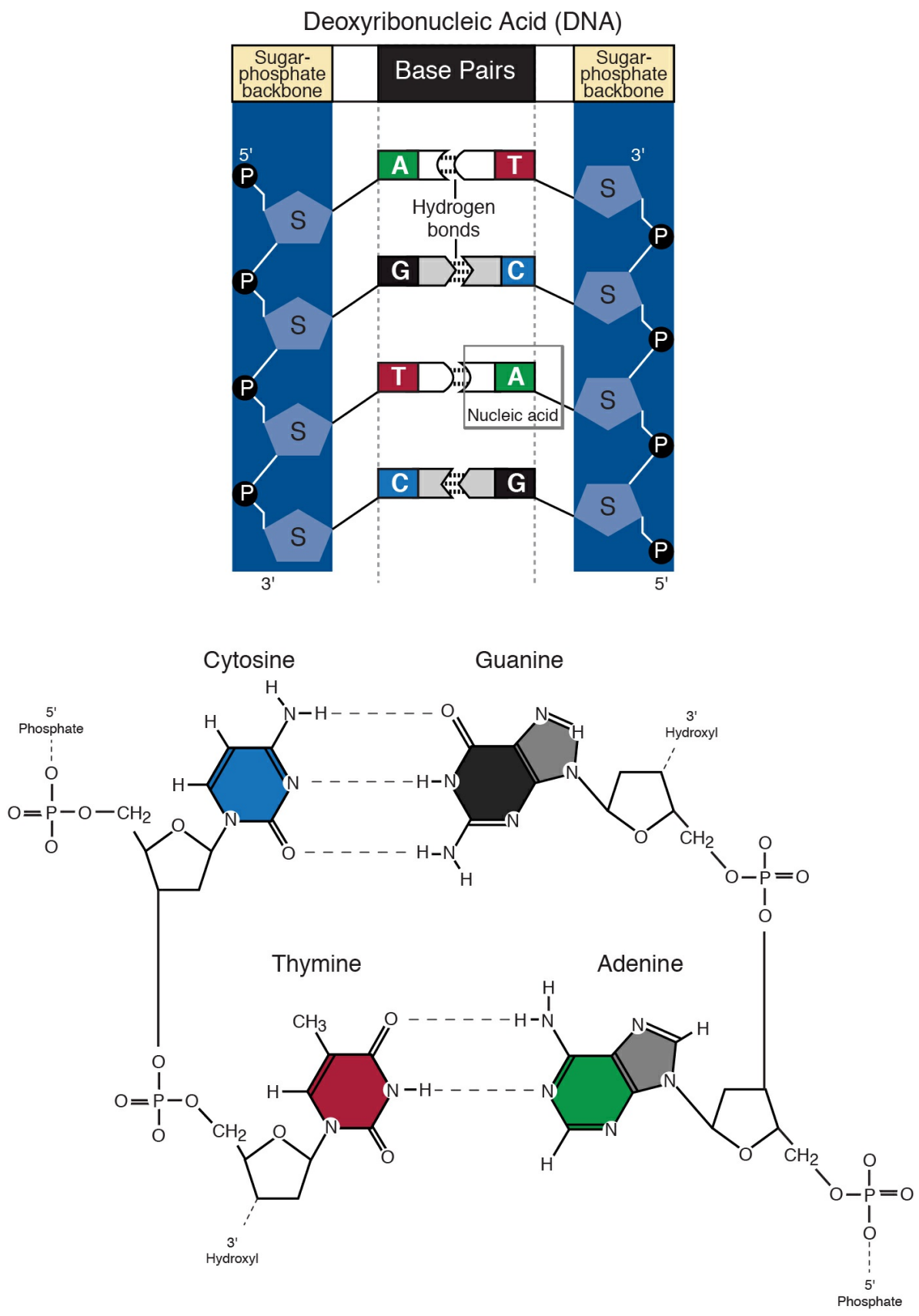